http://jmscr.igmpublication.org/home/

ISSN (e)-2347-176x ISSN (p) 2455-0450

crossref DOI: https://dx.doi.org/10.18535/jmscr/v7i10.130

Journal Of Medical Science And Clinical Research

IGM Publication

An official Publication of IGM Publication

\title{
A comparative Study of Sonographic Parameters with Neonatal Ponderal index as a predictor of IUGR
}

\author{
Authors \\ Dr Simi A ${ }^{1}$, Dr Sapna Devi. D $\mathbf{P}^{2 *}$ \\ ${ }^{1,2}$ Assistant Professor, Dept. of O and G, SAT Hospital, Govt. Medical College, Trivandrum \\ *Corresponding Authors \\ Dr Sapna Devi. D P
}

Assistant Professor, Dept. of O and G, SAT Hospital, Govt. Medical College, Trivandrum, India

\begin{abstract}
Background: Intrauterine growth restriction is one of the commonest problems which increases the perinatal morbidity. The diagnosis of impaired fetal growth is still a challenge as the standards of fetal measurements of growth, both clinical and ultrasonographic parameters vary depending on the race and geographic location

Materials and Methods: This is a prospective study conducted at SAT hospital Thiruvanthapuram. Cases fulfilling the inclusion criteria were included in the study over a period of 6 months. Clinical and ultrasound parameters at the time of detection of IUGR was noted. These patients were followed up till delivery. At the time of delivery the neonatal ponderal index was calculated.

Results: Among the sonographic parameters abdominal circumference and estimated fetal weight was found to be highly sensitive in predicting IUGR. .

Conclusions-Serial USS follow-up of abdominal circumference and estimated fetal weight can help obstetricians in early detection of IUGR before asking for costly investigations like Doppler, thus making checkups cost effective.

Keywords: IUGR, Abdominal circumference, sonographic estimated fetal weight, neonatal ponderal index.
\end{abstract}

\section{Introduction}

A growth restricted infant is defined as an infant who has not achieved its genetic growth potential in utero. The ability to reach an optimal birth weight results from the interaction between fetal growth potential and its environment

The diagnosis and management of impaired fetal growth is a problem because of the lack of a precise definition of intrauterine growth restriction and our ignorance about the individual fetal growth potential.

Currently accepted classification Of FGR is for very small for gestational age (VSGA); <3rd percentile) and, small for gestational age (SGA); $<10$ th percentile. But this misses growth restricted fetus with normal birth weight. The Ponderal index (PI) and mid arm/head circumference (MAC/HC) ratio are two other measurements of body proportionality used to identify atrisk IUGR infants ${ }^{1,2}$,

The ponderal index ([birth weight in grams/crown heel length $]^{3} \times 100$ ) has a high accuracy for the identification of SGA. It correlates more closely with perinatal morbidity and mortality than 
traditional birth weight percentiles. Miller andHassanein $^{3}$ proposed that a full term infant is growth retarded if his PI is <2.2. According to Man Mohan et al. ${ }^{4}$ in a term infant PI $<2.25$ should be an indicator of intrauterine undernutrition. Ponderal index relies on the principle that length is spared at the expense of weight during period of acute malnutrition; In this study Fetal growth retardation has been confirmed by calculating the neonatal ponderal index in all antenatally detected IUGR cases.

\section{Aims and Objectives}

1. To find out the sensitivity of symphysiofundal height measurement in predicting IUGR.

2. To find out the sensitivity of $\mathrm{HC} / \mathrm{AC}$, FL/AC, Abdominalcircumference, AFI $<5$ and sonographic estimated fetal weight in predicting IUGR.

3. To assess the mode of delivery of IUGR fetuses

4. To assess the perinatal outcome of IUGR fetuses.

\section{Materials and Methods}

This is a prospective study conducted in department of obstetrics and gynecology, SAT hospital, GMC, Thiruvananthapuram, Kerala.

\section{Inclusion Criteria}

All singleton pregnancies who were identified as IUGR clinically or by USS.

1) Clinically symphysiofundal height, gestational age discrepancy of $\geq 4$ weeks.

2) Clinically suspected decreased liquor volume

3) USS parameters include

i) Abnormal $\mathrm{HC} / \mathrm{AC}$ ratio $(\geq 1)$

ii) Abnormal FL/AC ratio (> 22.1)

iii) Oligamnios $\mathrm{AFI} \leq 5$.

\section{Exclusion Criteria}

1. Multiple Pregnancy

2. Those who are unsure of their LMP.

\section{Conduct of study}

All consecutive cases admitted in SAT Hospital during the period of study were recruited. The patients who matched the criteria of induction were selected and examined. Symphysiofundal height was measured. Any measurement of fundal height falling $3 \mathrm{cms}$ or below the regression line was considered predictive of 1UGR. The regression line by Mathai $^{5}$ et al was taken as standard. Presentation of the fetus and fetal heart was noted.

USS was done at SAT Hospital itself using B mode ultra sound machine with $3.5 \mathrm{MH} 3$ probe (Aloka) available in this hospital BPD, HC, AC, FL, AFI and EFW was measured. ${ }^{6}$ Estimated fetal weight is measured in our machine using the Hadlock's formula.

After the sonogram, the patients are followed up till delivery, Mode of delivery was noted. Growth restriction was confirmed by physical examination of neonate at birth and neonatal ponderal index was calculated using the formula Weight in grams

(Height in $\mathrm{cm})^{3}$

Weight of the baby was recorded with in $24 \mathrm{hrs}$ of delivery using electronic fetal weighing machine, with a digital readout. This machine is said to have an accuracy of $\pm 5 \mathrm{~g}$. Length of the baby was also measured within 24 hours of delivery using the infantometer available in NICU.

All infants with neonatalponderal index $<2.25$ was taken as abnormal ${ }^{(4)}$. This data was computed along with each of the sonographic parameters in a two by two table and sensitivity and specificity of each sonographic parameter was calculated.

Any complications requiring admission to $\mathrm{NlCU}$ was noted. These babies were followed uptillimmediate perinatal period \& outcome was assessed.

\section{Observations and Results}

Table 1 Distribution according to age

\begin{tabular}{|l|c|}
\hline Mean & 24.4 \\
\hline S.D & 4.4 \\
\hline Median & 23 \\
\hline Range & $19-37$ years \\
\hline
\end{tabular}


24.4 yrs. Maximum age was :17 years minimum age was 19 years.

Table II Distribution according to parity

\begin{tabular}{|l|c|c|}
\hline Parity & & $\%$ \\
\hline Primi & 53 & $70.7 \%$ \\
\hline Multigravida & 21 & 28 \\
\hline Grandmulti & 1 & $1.3 \%$ \\
\hline & 75 & $100 \%$ \\
\hline
\end{tabular}

\section{Distribution according to parity}

Majority of women were Primisie $70.7 \%$

Table III Distribution according to referral status

\begin{tabular}{|l|c|c|}
\hline Booked & 27 & $36 \%$ \\
\hline Un Booked & 1 & $1.3 \%$ \\
\hline Booked outside & 47 & $62.7 \%$ \\
\hline & 75 & $100 \%$ \\
\hline
\end{tabular}

Majority of cases were booked outside ie $62.7 \%$. one unbooked case of an illiterate elderly primi was there.

Table IV Distribution of risk factors

\begin{tabular}{|l|c|c|}
\hline Hypertension complicating pregnancy & 5 & 6.7 \\
\hline PIH & 18 & 24 \\
\hline Overt diabetes & 1 & 1.3 \\
\hline PIH c Co-existing GDM w other medical & 2 & 2.7 \\
\hline $\begin{array}{l}\text { Hypertension with } \\
\text { disorders }\end{array}$ & 2 & 2.7 \\
\hline Uterine anomalies & 1 & 1.3 \\
\hline Idiopathic & 46 & 61.3 \\
\hline & 75 & $100 \%$ \\
\hline
\end{tabular}

\section{\% Distribution of Risk factor}

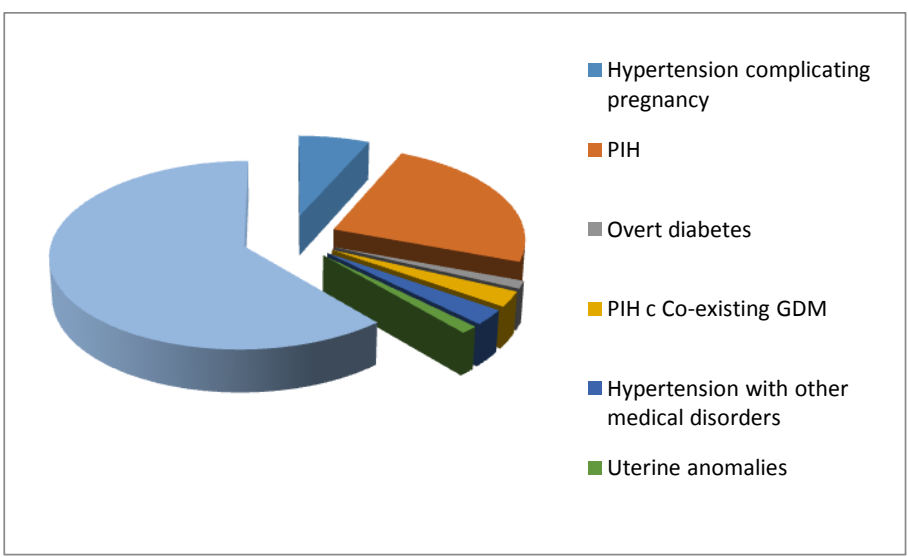

Table V Distribution according to $\mathrm{Hb}$

\begin{tabular}{|l|c|}
\hline Mean & 11.1 \\
\hline SD & 1.1 \\
\hline Median & 11 \\
\hline Range & $9-13.5$ \\
\hline
\end{tabular}

Mean hemoglobin was found to be $11.1 \mathrm{mg} \%$. Minimum Hemoglobin was $9 \mathrm{gm} \%$ and maximum level was $13.5 \mathrm{gm} \%$.
Table VI Distribution of mode of delivery

\begin{tabular}{|l|c|c|}
\hline & & $\%$ \\
\hline Spontaneous labour & 9 & 12 \\
\hline Induced labour & 30 & 40 \\
\hline Elective CS & 19 & 25.3 \\
\hline Emergency CS & 17 & 22.7 \\
\hline & 75 & 100 \\
\hline
\end{tabular}

Of the 75 cases $12 \%$ went in for spontaneous labor, $40 \%$ had induction of labour. Majority of paientsie $48 \%$ had casarian section either, emergency or lective $35.3 \%$ had elective CS and $22.7 \%$ had emergency CS.

Table VII Indications for emergency ceasarean

\begin{tabular}{|l|c|c|}
\hline Placenta previa & 1 & $5.9 \%$ \\
\hline Fetal distress & 8 & $47 \%$ \\
\hline Abnormal Doppler & 2 & $11.8 \%$ \\
\hline Abnormal presentation & 3 & $17.6 \%$ \\
\hline Abruption & 1 & $5.9 \%$ \\
\hline Failed induction & 2 & $11.8 \%$ \\
\hline
\end{tabular}

Out of the 17 emergency caesarian section $47.05 \%$ were for fetal distress defected during labour.

Table VIII Indications for elective caesarean

\begin{tabular}{|l|c|c|}
\hline Abnormal Doppler & 4 & $21 \%$ \\
\hline Previous LSCS & 2 & $10.5 \%$ \\
\hline Malpresentations & 4 & $21 \%$ \\
\hline Placenta previa & 1 & $5.3 \%$ \\
\hline IUGR & 8 & $42.2 \%$ \\
\hline Total & 19 & 100 \\
\hline
\end{tabular}

Elective caesarians were done for $42.2 \%$ of cases for severe IUGR and $21 \%$ cases were done for abnormal Doppler report.

Table IX Distribution of Birth weight

\begin{tabular}{|l|c|c|}
\hline$>2.5 \mathrm{~kg}$ & 5 & $6.7 \%$ \\
\hline $2-2.5$ & 30 & $40 \%$ \\
\hline $1.5-2$ & 25 & $33.3 \%$ \\
\hline$<1.5$ & 15 & $20 \%$ \\
\hline & 75 & $100 \%$ \\
\hline
\end{tabular}

Mean distribution of birth weight was $1898 \mathrm{gm}$ with minimum birth weight ranging from 875 gmto maximum of $2800 \mathrm{gm}$.

Table X Perinatal outcome

a) Apgar at 1 minute

\begin{tabular}{|l|c|c|}
\hline$>8$ & 64 & $88.9 \%$ \\
\hline $4-7$ & 7 & $9.7 \%$ \\
\hline$<4$ & 1 & $1.4 \%$ \\
\hline & 72 & $100 \%$ \\
\hline b) Perinatal morbidity & 52 & $69.3 \%$ \\
\hline c) Perinatal mortality & 5 & $6.6 \%$ \\
\hline
\end{tabular}


Table XI Perinatal mortality

\begin{tabular}{|l|l|l|}
\hline Still born & 1 & 20 \\
\hline IUD & 2 & 40 \\
\hline Perinatal death & 2 & 40 \\
\hline
\end{tabular}

Table XII Perinatal morbidity

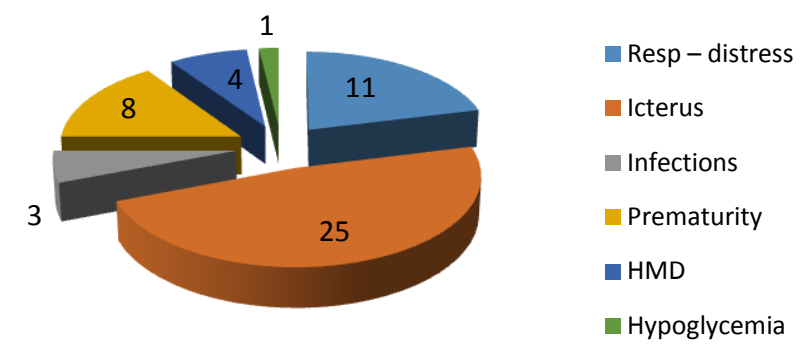

No morbidity was present in $28 \%$ of babies

\section{Discussion}

Out of 75 subjects the mean age distribution was found to be 24.4 yrs. This nearly corresponds to the meanage distribution of all females delivering in our hospital (ie. $21.3 \mathrm{yrs}$ ). Thus in our study the concept that extremes of maternalage increases the risk of FGR is not substantiated.

Among the 75 cases, commonest incidence of IUGR was in primiparas (70.66\%). This high incidence can be explained by the fact that hypertensive disorders of pregnancy forms a major risk factor for $\mathrm{IUGR}^{7}$. Generally preeclampsia is thought of as disease of first pregnancies.

$62.70 \%$ of cases were booked outside which is very high compared to general statistics our hospital showing $13 \%$ of all cases as booked outside. This can also be explained by the fact that detection of IUGR renders the pregnancy to be of high risk and need for referral to a tertiary care center becomes inevitable.

In this study $61.3 \%$ of pregnancies did not have any risk factor to account for their IUGR of fetus. Hypertensive disorders of pregnancy ${ }^{7}$ was found to be the most common risk factor associated with IUGR (36.1\%) of these PIH alone accounted for by $24 \%$, chronic hypertension complicating pregnancy was $6.7 \%$ PIH co-existing with GDM was found in $2.7 \%$ and Hypertension associated with other medical disorder and also $2.7 \%$. We had 2 cases of antiphospholipid antibody syndrome, who developed PIH in the 6th month of pregnancy. Though Anemia was analyzed as a separate risk factor in the study mean hemoglobin distribution among subjects were $11.1 \mathrm{gm} \%$. In the study by Ounsted et al, anema was not found to be an important risk factor. This substantiated in this study.

In this study, the sensitivity of symphysiofundal height is found to be $74.5 \%$. this is agreement with results of many studies. 8,9

Even though symphysiofundal height is said to be a simple, inexpensive screening method of IUGR, low sensitivity, high false positive rate, significant intra - inter observer variation makes this test along unsuitable for diagnostic purpose. ${ }^{9}$ Therefore if SGA is suspected it is necessary to supplement, fundal height measurement with ultrasonic biometry

Use of a customised fundal height chart improves accuracy to predect an SGA fetus ${ }^{19}$.

Sensitivity of $\mathrm{HC} / \mathrm{AC}$ ratio is found to be $35.6 \%$ in this study and specificity was found to be $62,5 \%$. Study by $\mathrm{Ott}^{10}$ et al in 1997 showed a sensitivity of $82 \%$ and Campbell and Thomas ${ }^{11}$ showed a sensitivity of $70 \%$

Colley ${ }^{12} \mathrm{NV}$ et al 1991 showed by their study that $\mathrm{HC} / \mathrm{AC}$ ratio are poorer than $\mathrm{AC}$ or EFW alone in predicting SGA or NPI $<25^{\text {th }}$ centile.

FL/AC ratio sensitivity is found to be $9.6 \%$ but Benson et al and Brown et al called it a poor predictor of IUGR ${ }^{12,13,14}$

In this study, abdominal circumference with sensitivity of $84.9 \%$ has emerged as the best sonographic parameter in predicting IUGR. Many studies have shown this and proposed AC as the best predictor of IUGR. ${ }^{14,15,16,17,18}$. Serial measurement of AC after 14 days improves 
the sensitivity of IUGR detection ${ }^{18}$

In this study sensitivity of AFI $<5$ in predicting IUGR is $25.4 \%$ According to RCOG $^{19}$ guidelines Amniotic fluid volume has a minimal value in diagnosing fetal growth restriction. A serial measurement of AFI have similarly disappointing results.

As the study by Philipson ${ }^{20}$ et a and Manning et $\mathrm{al}^{21}$, if oligohydramnios is detected on an ultrasound examination, the chance that IUGR is present is increased about fourfold and the sensitivity in these studies were shown to be $83 \%$. The clinician should have a heightened index of suspicion, seek confirmatory evidence and monitor fetal status carefully through delivery. Routine sonographic screening to detect oligamnios is not warrented.

In this study, estimated fetal weight is found to have a sensitivity of $84.7 \%$ as supported by many studies. ${ }^{14,15,16,17,18}$

Thus in this study Abdominal circumference and estimated fetal weight have emerged as the best predictor for IUGR fetus. This view has been supported by many studies. ${ }^{10,16}$ Infact serial measurement of $\mathrm{AC}$ and $\mathrm{EFW}$ (growth velocity) are superior to single estimate of $\mathrm{AC}$ or EFW. ${ }^{16}$

Abdominal circumference has both the highest sensitivity and greatest negative predictive value for the sonographic diagnosis of IUGR whether defined postnataly by the birth weight percentile or the ponderal index. The positive predictive value of a low AC percentile for growth restriction is about $50 \%$ in any given population. It is best not to label a fetus growth restricted and trigger expensive fetal surveillance unless the $\mathrm{AC}$ and sonographic estimate of weight is also abnormal. ${ }^{17}$ The positive predictive value of estimated fetal weight is greater. Such a patient should be followed up with doppler.

$47 \%$ of the above subjects were delivered by Caesarian section. This is much higher than the hospital caesarian rate of $27 \%$ during this period. $40 \%$ of the subjects had induced delivery. This is also higher than the general rate of induction in our hospital Because of the higher detection rate of intrauterine fetal asphyxia by doppler, the delivery rates by induction of labour is also higher. Majority of emergency cesareans were performed for fetal distress $(47.1 \%)$. This is also related to the intrapartum fetal monitoring in the labour room using CTG machine which is highly necessary as an IUGR baby is prone for severe fetal distress and neonatal birth asphyxia. Abnormal presentations were also seen in these subjects as the decreased liquor volume may restrict the mobility of fetus $(17.6 \%) .42 \%$ of the elective caesareans were done for severe IUGR oligamnios. $21 \%$ cases had abnormal Doppler vclocimetry these babies could not have withstood the stress of labour had they been induced.

The perinatal mortality was $6.6 \%$ and found to be comparable to other studies ${ }^{22,23}$ Of these two cases of intrauterine death was present.

Perinatal morbidity was very much increased in this study ie $69.3 \%$ compared to Bollapragada et al where morbidity is only $35 \%$. This could be explained by the increased intervention rates due to increased detection of intrauterine fetal distress by doppler study.

\section{Conclusion}

This study was conducted with an aim to find out the sensitivity of various sonographic parameters used routinely in our hospital tnpredicting IUGR. Most of the studies had used the gold standard of diagnosis as the immediate birth weight. But the main drawback of this outcome was that it failed to differentiate between the low birth weight infant from a growth retarded infant.

The present study utilized neonatal ponderal index as the gold standard in diagnosing lUGR.

Among the songraphic parameters, Abdominal circumference, and the sonographic estimated fetal weight was found to be highly sensitive in predicting IUGR, which is comparable to many other studies. 
Thus a fall in abdominal circumference less than 2 standard deviations from mean for that gestational age or a fall in estimated fetal weight less than 10th percentile from a mean for that gestational age should caution the obstetrician that fetus is going in for growth retardation.

Detection of fetal growth restriction helps in deciding the management of the case. If early onset to seek for congenital anomalies, if late onset to start strict fetal surveillance in order to detect early inutero fetal compromise.

FL/AC ratio was also found to have a sensitivity of $79.6 \%$. In detecting. IUGR, Thus FL/ AC ratio can also be used for prediction of IUGR. Symphysio fundal height if plotted using a customized chart could act as a good predictor of FGR.

Commonest risk factor leading to IUGR was found to be hypertensive disorders of pregnancy. Thus in such patients, obstetrician should be on the outlook of IUGR

As IUGR is a condition which warrants early intervention during early gestational age, increasing number of premature babies poses a great problem for the neonatologist and Neonatal ICU's equipped with better provisions of preterm care should be brought up.

\section{References}

1. Georgieff MK, Sasanow SR, Chockalingam UM, Pereira GR. A comparison of the mid- arm circumference/head circumference ratio and ponderal index for the evaluation of newborn infants after abnormal intrauterine growth. Acta Pædiatrica. 1988 Mar;77(2):214-9.

2. Metcoff J. Clinical assessment of nutritional status at birth: Fetal malnutrition and SGA are not synonymous. Pediatric Clinics of North America. 1994 Oct 1;41(5):875-91.

3. Miller HC, Hassanein K. Diagnosis of impaired fetal growth in newborn infants. Pediatrics. 1971 Oct 1;48(4):511-22
4. Mohan M, Prasad SR, Chellani HK, Kapani V. Intrauterine growth curves in north Indian babies: weight, length, head circumference and ponderal index. Indian pediatrics. 1990 Jan;27(1):43-51

5. .Mathai M. Prediction of small- forgestational age infants using a specially calibrated tape measure Br. j. Obstet Gynecol. 1988; 95,313-4

6. Callen PW. Ultrasonography in Obstetrics and Gynecology E-Book. Elsevier Health Sciences; 2011 Oct 17.

7. Ounsted M, Moar VA, Scott A. Risk factors associated with small- for- dates and large- for- dates infants. BJOG: An International Journal of Obstetrics \& Gynaecology. 1985 Mar;92(3):226-32.

8. Belizán J, Villar J, Nardin JC, Malamud J, De Vicuña LS. Diagnosis of intrauterine growth retardation by a simple clinical method: measurement of uterine height. American Journal of Obstetrics \& Gynecology. 1978 Jul 15;131(6):643-6

9. Calvert Jp, Crean EE, Newcombe RC, Pearson JF, Antenatal screening by measurement of symphysiofundal height. BMJ (din Res Ed) 1982; 285; 846-9.

10. Ott WJ. Sonographic diagnosis of intrauterine growth restriction. Clinical obstetrics and gynecology. 1997 Dec 1;40(4):787-95

11. Campbell S, Thomas A. Ultrasound measurement of the fetal head to abdomen circumference ratio in the assessment of growth retardation. BJOG: An International Journal of Obstetrics \& Gynaecology. 1977 Mar;84(3):165-74.

12. Colley NV Tremble JM, Henson CL, Cole TJ !lead circumference / Abdominal circumference ratio, Ponderal index and fetal malnutrition should $\mathrm{HC} / \mathrm{AC}$ ratio be abandonded 7 Br. J. Obstet Cynecol1991; 98, 524-7.

13. Benson CB, Doubilet PM, Saltzman DH, Jones TB. FL/AC ratio: poor predictor of 
intrauterine growth retardation. Investigative radiology. 1985 Oct;20(7): 727-30.

14. Brown HL, Miller JJ, Gabert HA, Kissling GR. Ultrasonic recognition of the smallfor-gestational-age fetus. Obstetrics and gynecology. 1987 Apr;69(4):631-5.

15. Hadlock FP, Harrist RB, Sharman RS, Deter RL, Park SK. Estimation of fetal weight with the use of head, body, and femur measurements-a prospective study. American journal of obstetrics and gynecology. 1985 Feb 1;151(3):333-7.

16. Chang TC, Robson SC, Boys RJ, Spencer JA. Prediction of the small for gestational age infant: which ultrasonic measurement is best?. Obstetrics and gynecology. 1992 Dec;80(6):1030-8.

17. Baschat AA, Weiner CP. Umbilical artery Doppler screening for detection of the small fetus in need of antepartum surveillance. American journal of obstetrics and gynecology. 2000 Jan 1;182(1):154-8.

18. Divon MY, Chamberlain PF, Sipos L, Manning FA, Platt LD. Identification of the small for gestational age fetus with the use of gestational age-independent indices of fetal growth. American journal of obstetrics and gynecology. 1986 Dec 1;155(6):1197-201.

19. No GT. The investigation and management of the small-for-gestationalage fetus.

20. Philipson EH, Sokol RJ, Williams T. Oligohydramnios: clinical associations and predictive value for intrauterine growth retardation. American Journal of Obstetrics \&Gynecology. 1983 Jun 1;146(3):271-8.
21. Chamberlain PF, Manning FA, Morrison I, Harman CR, Lange IR. Ultrasound evaluation of amniotic fluid volume: I. The relationship of marginal and decreased amniotic fluid volumes to perinatal outcome. American journal of obstetrics and gynecology. 1984 Oct 1;150(3):245-9.

22. .Scott KE, Usher R. Fetal malnutrition: its incidence, causes, and effects. American Journal of Obstetrics \& Gynecology. 1966 Apr 1;94(7):951-63.

23. Bollapragada S. Wani R., Raval MY. Intrauterine growth retardation- Effect on outcome. July ed.Jr. of Obstetrics and Gynaecology of India. 1996, 477-481. 